\title{
KERAGAMAN DAN POTENSI PEMANFAATAN VEGETASI GULMA PASCA PERTANAMAN PADI DI DESA PENGGARON KECAMATAN MOJOWARNO KABUPATEN JOMBANG
}

\author{
Anggi Indah Yuliana*, Mucharommah Sartika Ami** \\ * Agroekoteknologi, Universitas KH. A. Wahab Hasbullah \\ **Pendidikan Biologi, Universitas KH. A. Wahab Hasbullah
}

Correspondence Author: anggiiyk@unwaha.ac.id

\begin{tabular}{|c|c|}
\hline Info Artikel : & ABSTRACT \\
\hline $\begin{array}{l}\text { Sejarah Artikel : } \\
\text { Menerima : } \\
27 \text { Okt } 2020 \\
\text { Revisi : } \\
25 \text { Nov } 2020 \\
\text { Diterima : } \\
27 \text { Nov } 2020 \\
\text { Online : } \\
\text { 09 Jan } 2021 \\
\text { Keyword : } \\
\text { diversity, weed } \\
\text { vegetation, } \\
\text { utilization, rice } \\
\text { fields }\end{array}$ & $\begin{array}{l}\text { A field study aims to determine the diversity and potential utilization of weed } \\
\text { vegetation that grows after rice planting. This research was carried out in } \\
\text { paddy fields after monoculture rice planting in Penggaron Village, Mojowarno } \\
\text { District, Jombang Regency in July - September 2020. Sampling was based on } \\
\text { the quadratic sampling method with sample plots arranged randomly. In each } \\
\text { plot the data taken is the name, number and canopy (area of cover) of each } \\
\text { plant species to determine density, dominance and frequency. Data analysis } \\
\text { includes vegetation analysis to determine Summed Dominance Ratio (SDR) } \\
\text { and biodiversity analysis calculated using the Shannon - Wienner diversity } \\
\text { index. The results of this study were } 26 \text { types of weed vegetation were found in } \\
\text { post-rice planting land. The dominant vegetation types include Oryza sativa L } \\
\text {.; Limnocharis flava (L.) Buchenav; Phyllanthus urinaria L .; Monochoria } \\
\text { vaginalis (Burm.f.) pressl; and Cleome viscosa L with an SDR value of } \geq \\
\text { 5.30\%. A total of } 15 \text { types of weeds have the potential to be used as a source of } \\
\text { food, animal feed, and traditional medicine. }\end{array}$ \\
\hline & INTISARI \\
\hline $\begin{array}{l}\text { Kata Kunci : } \\
\text { keragaman, } \\
\text { vegetasi gulma, } \\
\text { pemanfaatan, } \\
\text { lahan } \\
\text { persawahan }\end{array}$ & $\begin{array}{l}\text { Sebuah penelitian lapang bertujuan untuk mengetahui keragaman dan potensi } \\
\text { pemanfaatan vegetasi gulma yang tumbuh pasca pertanaman padi. Penelitian } \\
\text { di lahan persawahan pasca pertanaman padi monokultur Desa Penggaron } \\
\text { Kecamatan Mojowarno Kabupaten Jombang pada bulan Juli - September } \\
\text { 2020. Pengambilan sampel berdasarkan metode sampling kuadrat dengan } \\
\text { petak contoh yang disusun secara acak. Pada setiap plot data yang diambil } \\
\text { adalah nama, jumlah dan tajuk (luas penutup) dari masing-masing jenis } \\
\text { tumbuhan untuk menentukan kerapatan, dominansi dan frekuensi. Analisis } \\
\text { data meliputi analisis vegetasi untuk mengetahui Summed Dominance Ratio } \\
\text { (SDR) dan analisis keragaman hayati yang dihitung dengan indeks diversitas } \\
\text { Shanon - Wienner. Hasil penelitian } 26 \text { jenis vegetasi gulma ditemukan pada } \\
\text { lahan pasca pertanaman padi. Jenis vegetasi yang dominan antara lain Oryza } \\
\text { sativa L.; Limnocharis flava (L.) Buchenav; Phyllanthus urinaria L.; }\end{array}$ \\
\hline
\end{tabular}


Monochoria vaginalis (Burm.f.) pressl; dan Cleome viscosa L dengan nilai $S D R \geq 5.30 \%$. Sebanyak 15 jenis gulma memiliki potensi untuk dimanfaatkan sebagai sumber pangan, pakan ternak, dan obat tradisional.

\section{PENDAHULUAN.}

Di wilayah Indonesia lahan sawah untuk pertanaman padi sangat umum ditemukan, terutama di kawasan pedesaan. Hal ini tidak terlepas dari peran beras sebagai makanan pokok masyarakat Indonesia sehingga tanaman padi dibudidayakan secara intensif dengan sistem monokultur. Meskipun sistem monokultur menjadi salah satu penopang produksi pangan bagi masyarakat Indonesia namun proses penyederhanaan lingkungan menjadi pertanian monokultur telah menyebabkan terjadinya erosi keragaman hayati (Saleh, 2018). Praktek pertanaman padi monokultur telah menggerus vegetasi alami pada agroekosistem sawah karena dianggap sebagai tanaman pengganggu padi (gulma). Pengendalian vegetasi gulma yang tidak ramah lingkungan dengan menggunakan herbisida berpotensi menghilangkan vegetasi yang bermanfaat bagi manusia. Pelestarian diperlukan karena peran masing-masing vegetasi sebagai sumber pangan, obat-obatan dan konservasi alam (Njurumana, 2016).

Dalam kondisi alami, lahan sawah ditumbuhi berbagai macam vegetasi baik dari golongan rerumputan maupun golongan daun lebar. Kehidupan komunitas vegetasi pada agroekosistem padi sawah dipengaruhi oleh ruang (spasial) tumbuh dan waktu (Suryatini, 2018). Selain itu kecepatan, arah dan komposisi suksesi ditentukan oleh spesies yang ada dan berkembang biak secara cepat setelah gangguan. Beberapa spesies nantinya akan muncul dan paling dapat beradaptasi dengan lingkungan baru, sehingga mendominasi lingkungan baru tersebut (Mardiyanti et al., 2013).

Tiap spesies vegetasi memainkan peranan dalam keseimbangan suatu ekosistem, bahkan tidak jarang vegetasi tersebut juga bermanfaat bagi manusia. Dengan demikian, kegiatan analisis vegetasi memainkan peranan penting dalam upaya penyediaan informasi tentang kondisi dan jenis vegetasi pada suatu agroekosistem. Penggalian potensi pemanfaatan vegetasi pada agroekosistem padi juga sangat penting dilakukan karena berkaitan pemilihan teknologi pengendalian gulma secara ramah lingkungan. Oleh karena itu penelitian ini bertujuan selain mengetahui keragaman vegetasi gulma, juga menggali potensi kemanfaatannya bagi manusia.

\section{METODE PENELITIAN.}

Penelitian ini dilaksanakan di lahan persawahan pasca pertanaman padi monokultur Desa Penggaron Kecamatan Mojowarno Kabupaten Jombang pada bulan Juli - September 2020. Lahan sawah pasca pertanaman padi dibiarkan /diberakan terlebih dahulu selama satu bulan agar vegetasi gulma yang ada dapat tumbuh dan berkembang. Penelitian ini termasuk jenis penelitian deskriptif kuantitatif yang dilakukan dengan mengumpulkan data kemudian mengidentifikasi dan mendeskripsikan keragaman vegetasi gulma. Pengambilan sampel berdasarkan metode sampling kuadrat dengan petak contoh yang disusun secara acak. Bahan dan alat yang digunakan adalah kantong plastik untuk tempat contoh gulma yang diambil, bilah kayu untuk membuat petak kuadrat berukuran $1 \mathrm{~m}$ x $1 \mathrm{~m}$, kawat kasa untuk tempat mencuci gulma, sabit, serta karung plastik sebagai tempat contoh vegetasi gulma yang telah diambil, alat tulis, dan kamera.

Pengambilan sampel dilakukan dengan metode kuadrat. Petak ukur pengamatan gulma dibuat persegi ukuran 1 x $1 \mathrm{~m}$ diulang lima kali dan diletakkan secara diagonal pada plot lahan. Pada setiap plot data yang diambil adalah nama, jumlah dan tajuk (luas penutup) dari masing- 
masing jenis tumbuhan untuk menentukan kerapatan, dominansi dan frekuensi. Vegetasi gulma yang tumbuh pada setiap petak contoh dipanen dan di masukkan kedalam kantong plastik kemudian dicuci, ditiriskan, diidentifikasi untuk mengetahui spesies gulma.

Analisis data meliputi analisis vegetasi dan analisis keragaman hayati. Analisis Vegetasi dilakukan untuk mengetahui Summed Dominance Ratio (SDR), sedangkan untuk menentukan tingkat keragaman hayati (jenis gulma) diukur heterogenitas yang dihitung dengan indeks diversitas Shanon - Wienner (Triharso, 2004). Untuk mengetahui potensi kemanfaatan gulma dilakukan analisis etnobotani melalui wawancara terhadap informan (masyarakat desa) dan studi pustaka.

\section{HASIL DAN ANALISA.}

\subsection{Komposisi dan keragaman vegetasi gulma}

Dari hasil pengamatan yang dilakukan pada lahan pasca pertanaman padi di Desa Penggaron Kecamatan Mojowarno Kabupaten Jombang, telah ditemukan 26 jenis vegetasi gulma. Total jumlah individu gulma yang ditemukan pada petak contoh sebanyak 327 gulma. Nilai Summed Dominance Ratio (SDR) dari masing-masing jenis gulma tersaji pada Tabel 1. Padi menjadi vegetasi yang mendominasi dengan nilai SDR 27,84\%. Vegetasi padi yang muncul setelah panen dinamakan singgang. Singgang merupakan tunas atau anakan yang tumbuh dari tunggul padi sehabis panen. Singgang padi juga dapat tumbuh dan menghasilkan beras seperti tanaman padi petak utama meskipun dengan kemampuan produksi yang lebih rendah, namun masa panen padi dari tanaman singgang lebih singkat yaitu 2 bulan dengan kisaran hasil $26-57 \%$ dari panen utama (Susilowati et al., 2012).

Tabel 1. Komposisi vegetasi gulma pasca pertanaman padi.

\begin{tabular}{|r|l|l|r|c|}
\hline No & Jenis Gulma & Nama Lokal & \multicolumn{1}{|l|}{$\Sigma$} & SDR (\%) \\
\hline 1 & Marsilea crenata L. & Semanggi & 13 & 5.05 \\
\hline 2 & Oriza sativa L & Padi & 105 & 27.84 \\
\hline 3 & Limnocharis flava (L.) Buchenav & Genjer & 9 & 5.69 \\
\hline 4 & Physalis minima L. & Ciplukan & 4 & 3.59 \\
\hline 5 & Mimosa pudica L & Putri malu & 13 & 4.69 \\
\hline 6 & Eleusine indica (L.) Gaernt & Rumput lulangan & 8 & 5.18 \\
\hline 7 & Cleome viscosa L & Rumput mamang & 19 & 5.30 \\
\hline 8 & Echinochloa crus- galli (L.) Bcauv. & Rumput jawan & 5 & 2.83 \\
\hline 9 & Sphaeranthus africanus L. & Rumput patah kamudi & 3 & 2.26 \\
\hline 10 & Alternanthera selssilis (L.) DC. & Rumput kremah & 7 & 3.59 \\
\hline 11 & Fimbristylis fusca (Nees) C.B. Burnt & - & 2 & 1.97 \\
\hline 12 & Phyllanthus urinaria L. & Meniran & 10 & 5.48 \\
\hline
\end{tabular}


Lanjutan Tabel 1. Komposisi vegetasi gulma pasca pertanaman padi.

\begin{tabular}{|l|c|c|c|c|}
\hline 13 & Monochoria vaginalis (Burm.f.) pressl. & Rumput wewehan & 8 & 5.34 \\
\hline 14 & Rorippa indica L & - & 10 & 4.87 \\
\hline 15 & Merremia vitifolia (Burm f.) Hallier f & Rumput mantangan & 5 & 2.46 \\
\hline 16 & Merremia hederacea (Burm f) Hallier f & - & 14 & 5.03 \\
\hline 17 & Vigna radiata (L.) R.Wilczek & Kacang hijau & 4 & 2.85 \\
\hline 18 & Cleome viscosa L. & Maman kuning & 15 & 3.18 \\
\hline 19 & Amaranthus hybridus L. & Bayam kakap & 7 & 3.71 \\
\hline 20 & Salvia sp. & Sage & 2 & 1.97 \\
\hline 21 & Lindernia crustaceae (L.) f.muell & Brobos kebo & 7 & 3.65 \\
\hline 22 & Cleome chelidonii L.f. & - & 16 & 4.99 \\
\hline 23 & Trianthema portulacastrum L. & Krokot daun bulat & 6 & 1.71 \\
\hline 24 & Leonurus sibiricus L. & - & 18 & 5.01 \\
\hline 25 & Euphorbia hirta L. & Patikan kebo & 7 & 3.77 \\
\hline 26 & Peperomia pellucida (L.) & Sirih cina & 1 & 1.02 \\
\hline & Total $\quad$ & 327 & \\
\hline
\end{tabular}

Vegetasi gulma yang mendominasi setelah singgang padi adalah Limnocharis flava (L.) Buchenav dengan nama lokal genjer (SDR 5,69\%), diikuti oleh Phyllanthus urinaria L dengan nama lokal meniran (SDR 5.48\%), Monochoria vaginalis (Burm.f.) pressl. dengan nama lokal rumput wewehan (SDR 5.34\%), dan Cleome viscosa L dengan nama lokal rumput mamang (SDR $5.30 \%$ ). Nilai SDR menunjukkan dominansi vegetasi pada suatu pertanaman. Vegetasi yang mempunyai nilai SDR kemungkinan menang atau mampu bersaing dalam suatu daerah tertentu, mempunyai toleransi yang tertinggi, dan cocok dengan habitatnya dibandingkan dengan jenis lainnya. Vegetasi pada area persawahan selalu mengalami kerusakan secara periodik karena pengolahan tanah, atau karena pengendalian, namun terdapat vegetasi gulma selalau muncul pada area persawahan tersebut. Pemunculan gulma pada area persawahan dapat dikategorikan sebagai suksesi sekunder, komunitasnya dapat berubah secara progresif maupun retrogresif (Purnomo, 2011).

Tabel 2. Indeks keragaman vegetasi gulma gulma pasca pertanaman padi.

\begin{tabular}{|l|l|l|}
\hline Jenis Lahan & Indeks keragaman $\left(\mathrm{H}^{\prime}\right)$ & Keterangan \\
\hline Pasca pertanaman padi monokultur & 2,671 & sedang \\
\hline
\end{tabular}

Indeks keragaman $\left(\mathrm{H}^{\prime}\right)$ vegetasi dapat dihitung dengan menggunakan indeks ShannonWeaver. Diketahuinya nilai $\mathrm{H}^{\prime}$ bertujuan untuk mengetahui presentase keragaman suatu organisme dalam suatu ekosistem. H' bertujuan untuk menentukan keterangan jumlah suatu spesies yang ada pada suatu waktu dalam komunitas tertentu. Perhitungan $\mathrm{H}^{\prime}$ gulma di lahan persawahan pasca pertanaman padi didapatkan pada daerah ini tergolong sedang (Tabel 2). Indeks keragaman menggambarkan tingkat keragaman pada suatu komunitas, tingginya keragaman pada suatu komunitas menunjukkan semakin mantap atau stabilnya ekosistem tersebut. Semakin tinggi nilai keragaman jenis maka tingkat keragamannya semakin besar, sebaliknya nilai indeks keragaman vegetasi yang rendah menunjukkan telah terjadi tekanan terhadap vegetasi (Oktaviani et al., 2015). Tekanan vegetasi lahan persawahan dapat berupa faktor alam seperti bencana 
kekeringan maupun faktor campur tangan manusia seperti tindakan pengolahan tanah intensif dan pengendalian gulma dengan herbisida.

\subsection{Potensi Pemanfaatan Vegetasi Gulma Pasca Pertanaman Padi}

Beberapa jenis vegetasi gulma yang tumbuh pada lahan pasca pertanaman padi memiliki potensi kemanfaatan baik untuk keperluan manusia atau untuk pakan ternak, bahkan beberapa jenis dapat dimanfaatkan sebagai sumber obat-obatan tradisional. Sebanyak 15 jenis gulma memiliki potensi untuk dimanfaatkan dalam berbagai keperluan (Tabel 3) diantaranya 7 jenis gulma dapat dimanfaatkan sebagai sumber pangan, 2 jenis untuk sumber pakan dan 6 jenis lainnya sebagai tumbuhan berkhasiat obat.

Tabel 3. Potensi pemanfaatan jenis vegetasi gulma yang tumbuh pasca pertanaman padi.

\begin{tabular}{|c|c|c|c|}
\hline No & Nama spesies & Manfaat & $\begin{array}{l}\text { Keterangan } \\
\text { (Khasiat/pemanfaatan) }\end{array}$ \\
\hline 1. & Marsilea crenata $\mathrm{L}$. & Bahan pangan & Sayuran \\
\hline 2. & Oryza sativa $\mathrm{L}$ & Bahan pangan & Penghasil beras \\
\hline 3. & Limnocharis flava (L.) Buchenav & Bahan pangan & Sayuran \\
\hline 4. & Physalis minima L. & Bahan pangan & Buah \\
\hline 5. & Mimosa pudica $\mathrm{L}$ & Pakan ternak & - \\
\hline 6. & Eleusine indica (L.) Gaernt & Tanaman obat & $\begin{array}{l}\text { Sebagai obat diare } \\
\text { (Badrunasar dan Santoso, 2016) }\end{array}$ \\
\hline 7. & Sphaeranthus africanus L. & Tanaman obat & $\begin{array}{l}\text { Sebagai obat epilepsy, penyakit } \\
\text { kuning (jaundice), hepatopathy } \\
\text { dan gastropathy (Alimah, 2013) }\end{array}$ \\
\hline 8. & Phyllanthus urinaria $\mathrm{L}$. & Tanaman obat & $\begin{array}{l}\text { Sakit kuning (lever), malaria, } \\
\text { demam, ayan, batuk, haid lebih, } \\
\text { disentri, luka bakar, luka koreng, } \\
\text { dan jerawat } \\
\text { (Badrunasar dan Santoso, 2016). }\end{array}$ \\
\hline 9. & Monochoria vaginalis (Burm.f.) pressl. & Pakan ternak & - \\
\hline 10. & Rorippa indica $\mathrm{L}$ & Tanaman obat & $\begin{array}{l}\text { Sebagai penurun panas, } \\
\text { antiracun, peluruh air seni, } \\
\text { mencairkan dahak (mukolitik), } \\
\text { antibakteri. } \\
\text { (Badrunasar dan Santoso, 2016) }\end{array}$ \\
\hline 11. & Vigna radiata (L.) R.Wilczek & Tanaman pangan & $\begin{array}{l}\text { Biji dimanfaatkan sebagai bahan } \\
\text { makanan }\end{array}$ \\
\hline 12. & Cleome viscosa $\mathrm{L}$. & Tanaman obat & $\begin{array}{l}\text { Sebagai obat rematik } \\
\text { (Setyawati et al., 2015) }\end{array}$ \\
\hline 13. & Amaranthus hybridus L. & Tanaman pangan & Sayuran \\
\hline 14. & Euphorbia hirta L. & Tanaman obat & $\begin{array}{l}\text { Radang tenggorokan, bronkhitis, } \\
\text { asma, disentri, radang perut, } \\
\text { Diare, kencing darah, radang }\end{array}$ \\
\hline
\end{tabular}




\begin{tabular}{|l|l|l|l|} 
& & & $\begin{array}{l}\text { kelenjar susu, eksema } \\
\text { (Badrunasar dan Santoso, 2016) }\end{array}$ \\
\hline 15. & Peperomia pellucida $($ L.) & Tanaman pangan & Sayuran \\
\hline
\end{tabular}

Jenis vegetasi yang dapat dimanfaatkan sebagai sumber pangan antara lain Marsilea crenata L.; Oryza sativa L.; Limnocharis flava (L.) Buchenav; Physalis minima L.; Vigna radiata (L.) R.Wilczek; Amaranthus hybridus L.; dan Peperomia pellucida (L.). Sebagian besar vegetasi sumber pangan ini dapat dimanfaatkan sebagai sayuran hijau. Adapun jenis vegetasi gulma yang dapat dimanfaatkan sebagai bahan obat tradisional antara lain Eleusine indica (L.) Gaernt; Sphaeranthus africanus L.; Phyllanthus urinaria L.; Rorippa indica L; Cleome viscosa L.dan Euphorbia hirta L. Di sisi lain, vegetasi Mimosa pudica L dan Monochoria vaginalis (Burm.f.) pressl. Bermanfaat sebagai sumber pakan ternak ruminansia. Informasi potensi pemanfaatan vegetasi gulma dapat dijadikan sebagai pertimbangan dalam pemilihan teknik pengendaliannya.

\section{KESIMPULAN}

Terdapat 26 jenis vegetasi gulma ditemukan pada lahan pasca pertanaman padi. Jenis vegetasi yang dominan antara lain Oryza sativa L.; Limnocharis flava (L.) Buchenav; Phyllanthus urinaria L.; Monochoria vaginalis (Burm.f.) pressl; dan Cleome viscosa $\mathrm{L}$ dengan nilai SDR $\geq$ $5.30 \%$. Sebanyak 15 jenis gulma memiliki potensi untuk dimanfaatkan sebagai sumber pangan, pakan ternak, dan obat tradisional.

\section{ACKNOWLEDGEMENTS}

Terima kasih tim peneliti sampaikan kepada pihak Kementerian Riset dan Teknologi / Badan Riset dan Inovasi Nasional Republik Indonesia dan Lembaga Penelitian dan Pengabdian pada Masyarakat Universitas KH. A. Wahab Hasbullah yang sudah mendukung dan membantu pelaksanaan kegiatan penelitian ini. Disampaikan juga terima kasih kepada seluruh pihak yang membantu dan mendukung pelaksanaan kegiatan ini. 


\section{DAFTAR PUSTAKA}

Alimah, Dewi. 2013. Medicinal Weeds From Peat Swamp Forest In Kalimantan. International Seminar Proceedings Forests \& Medicinal Plants for Better Human Welfare 10 - 12 September 2013. p $387-401$

Badrunasar, Anas dan Harry Budi Santoso. 2016. Tumbuhan Liar Berkhasiat Obat. Forda Press. Bogor

Indriyanto. 2006. Ekologi hutan. Bumi. Aksara Jakarta

Mardiyanti D. E., K. P. Wicaksono, dan M. Baskara. 2013. Dinamika Keragaman Spesies Tumbuhan Pasca Pertanaman Padi. Jurnal Produksi Tanaman 1. 24 - 35

Njurumana, Gerson N. 2016. Masyarakat Desa Dan Manajemen Biodiversitas Flora Pada Sistem Pekarangan Di Kabupaten Sumba Tengah. Jurnal Penelitian Kehutanan Wallacea 5. 25-36

Oktaviani, Siti Indah, Didi Jaya Santri, dan Endang Daya. 2015. Keragaman Vegetasi Rawa di Kecamatan Tanjung Lago. Jurnal Lahan Suboptimal 4. 133 - 148.

Purnomo, Harsoyo. 2011. Perubahan Komunitas Gulma dalam Suksesi Sekunder Pada Area Persawahan dengan Genangan Air Yang Berbeda. Bioma 1. 83 - 96.

Saleh, Shahabuddin. 2018. Manajemen Agrobiodiversitas Untuk Mendukung Sistem Pertanian Berkelanjutan. Prosiding Seminar Nasional Biodeversity Conservation. Palu, 28 November 2018. Fakultas Kehutanan Universitas Tadulako. 17 - 23.

Setyawati, Titiek, Sari Narulita, Indra Purnama Bahri, dan Gilang Teguh Raharjo. 2015. A Guide Book to Invasive Alien Plant Species in Indonesia. LIPI. Bogor

Suryatini, Luh. 2018. Analisis Keragaman dan Komposisi Gulma Pada Tanaman Padi Sawah (Studi Kasus Subak Tegal Kelurahan Paket Agung Kecamatan Buleleng). Jurnal Sains dan Teknologi $7.77-89$.

Susilawati, B.S. Purwoko, H. Aswidinnoor, dan E. Santosa. 2012. Tingkat Produksi Ratun Berdasarkan Tinggi Pemotongan Batang Padi Sawah Saat Panen. Jurnal Agronomi Indonesia 40. 1 - 7 .

Triharso. 2004. Dasar-dasar Perlindungan Tanaman. Gadjah Mada University Press. Yogyakarta 